Revue des patrimoines

\title{
Bibliographie des travaux de Joël Perrin
}

Pierre Curie, Renaud Benoit-Cattin, Catherine Duboÿ-Lahonde et François Le Bœuf

\section{OpenEdition}

\section{Journals}

Édition électronique

URL : http://journals.openedition.org/insitu/1113

DOI : $10.4000 /$ insitu. 1113

ISSN : 1630-7305

\section{Éditeur}

Ministère de la culture

\section{Référence électronique}

Pierre Curie, Renaud Benoit-Cattin, Catherine Dubö̈-Lahonde et François Le Bœuf, « Bibliographie des travaux de Joël Perrin », In Situ [En ligne], 1 | 2001, mis en ligne le 20 janvier 2012, consulté le 20 avril 2019. URL : http://journals.openedition.org/insitu/1113 ; DOI : 10.4000/insitu.1113

Ce document a été généré automatiquement le 20 avril 2019.

\section{(c)}

In Situ Revues des patrimoines est mis à disposition selon les termes de la licence Creative Commons Attribution - Pas d'Utilisation Commerciale - Pas de Modification 4.0 International. 


\section{Bibliographie des travaux de Joël Perrin}

Pierre Curie, Renaud Benoit-Cattin, Catherine Duboÿ-Lahonde et François Le Bœuf

Figure 1

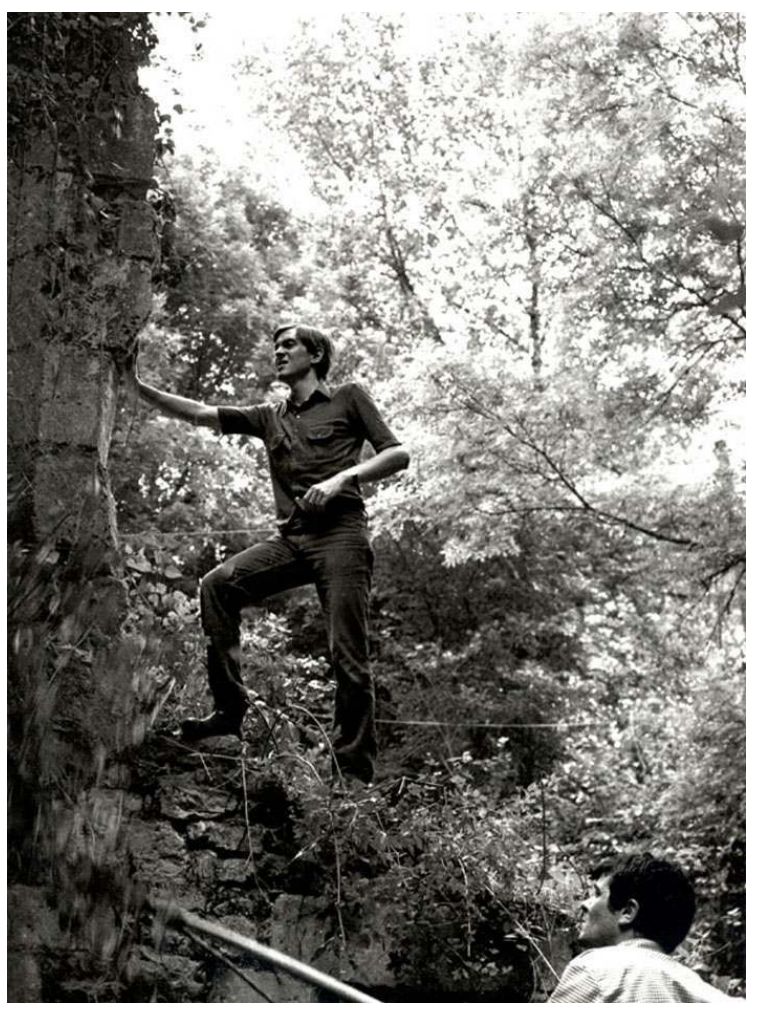

Joël Perrin en Aquitaine

(C) Inventaire général, ADAGP, 1969-1970 
1 Avec C. Duboÿ-Lahonde. Reliquaires et croix de procession du Béarn, cat. exp. Pau : Musée national du château, 6 avril-5 mai 1977 (multigr.)

Dessins de Jean et Joseph Richier. Leur participation à l'atelier de Pierre 1er Biard. Bulletin de la Société de l'Histoire de l'Art français - 1976. Paris : De Nobele, 1978, p. 37-47.

Lembeye. Développement et morphologie d'une ville fortifiée (XIII ${ }^{\mathrm{e}-\mathrm{XVIII}}{ }^{\mathrm{e}}$ siècles). Revue de Pau et du Béarn, 1979, n 7, p. 43-51.

Avec J.-Cl. Lasserre. Notre-Dame de Bétharram. Pau : Marrimpouey Jeune, 1980. (Amis des églises anciennes du Béarn).

Le couvent des Grandes Carmélites de Bordeaux. Société archéologique de Bordeaux, 1985, $\mathrm{n}^{\circ}$ 76, p. 105-116.

Avec C. Claerr et M.-F. Jacops. L'autel et le tabernacle, de la fin du XVI ${ }^{\mathbf{e}}$ siècle au milieu du XIX' siècle. Revue de l'Art, 1986, nº 71, p. 47-70.

Lembeye. L'église. Pau, Impr. graphique Marrimpouey Suc., 1987 (Amis des églises anciennes du Béarn).

La chapelle et le tombeau des ducs d'Épernon à Cadillac. Bulletin de la Société archéologique de Bordeaux - 1986, t. LXXVII, Bordeaux, 1987, p. 29-44.

Avec P. Araguas, C. Duboÿ-Lahonde et J.-C Lasserre. Vic-Bilh, Morlaàs et Montanérès (cantons de Garlin, Lembeye, Thèze, Morlaàs, Montaner; Pyrénées-Atlantiques). Paris : Imprimerie nationale, 1989. (Inventaire topographique).

Le château de Cadillac. Boulogne : Ed. du Castelet, 1990.

Avec F. Le Bœuf. Les saints de Solesmes. Nantes : A.D.I.G., 1990. (Images du Patrimoine ; 69).

Avec D. Eraud, D. de Maynard et J. Salbert. Retables de Mayenne. Nantes : A.D.I.G., 1990. (Images du Patrimoine ; 74). Avec D. Eraud, D. de Maynard et J. Salbert. Retables de Mayenne. 303, 3e trimestre 1990, n XXVI, p. 82-91.

Avec G. Bresc-Bautier et F. Le Bœuf. Charles Hoyau, sculpteur du Mans. Bulletin de la Société de l'Histoire de l'Art français - 1991. Paris, 1992, p. 37-64.

Contribution (avec G. Bresc-Bautier) à Mieux vaut un vrai Delabarre qu'un faux Sarazin : le tombeau de Donadieu de Puycharic et le sculpteur Gervais Delabarre par F. de La Moureyre. Bulletin de la Société de l'Histoire de l'Art français - 1991. Paris, 1992, p. 65-90.

Contribution à Tableaux religieux du $\mathrm{XVII}^{\mathrm{e}}$ siècle à Montpellier par $\mathrm{F}$. Arnal et A. Chevalier. Montpellier, 1993. (Images du Patrimoine ; 122).

Plafonds à décor au XVII ${ }^{\mathrm{e}}$ siècle. Château des ducs d'Epernon, Cadillac (Gironde). Paris : CNMHS, 1996. (Le monument et ses artisans).

Avec le frère J.-M. Gueullette. Le château de Cadillac. Paris, Éditions du Patrimoine, 1999. (Itinéraires du Patrimoine).

Co-direction (avec S. Vasco Rocca) et contribution (avec C. Arminjon, R. Benoit-Cattin, C. Constans, C. Duboÿ-Lahonde, D. Piot-Morin, N. de Reyniès et H. Verdier) à la partie française de Thesaurus. Objets religieux du culte catholique (Religious Objects of the Catholic Faith; Corredo ecclesiastico di culto cattolico). Paris: Éditions du Patrimoine, 1999 (Rome, 2000 pour la version CD-Rom). 
INDEX

Mots-clés : inventaire général, en ligne, journal, revue électronique, revue numérique, périodique, patrimoine, histoire de l'art, peinture, école italienne, 16e siècle, 17e siècle, 18e siècle, France

Keywords : on line, electronic journal, ejournal, heritage, history of art, France, italian paintings, XVIIth century, XVIth century, XVIIIth century

\section{AUTEURS}

\section{PIERRE CURIE}

Conservateur du patrimoine, Sous-direction des études, de la documentation et de l'Inventaire, Hôtel de Vigny 10, rue du Parc Royal 75003 Paris. pierre.curie@culture.gouv.fr

\section{RENAUD BENOIT-CATTIN}

Conservateur du patrimoine, Sous-direction des études, de la documentation et de l'Inventaire, Hôtel de Vigny 10, rue du Parc Royal 75003 Paris

\section{CATHERINE DUBOŸ-LAHONDE}

Conservateur en chef, Service régional de l'Inventaire, DRAC Aquitaine 54, rue Magendie 33074 Bordeaux cédex

\section{FRANÇOIS LE BEEUF}

Chercheur, Service régional de l'Inventaire, DRAC Pays de la Loire 1, rue Stanislas Baudry 44035 Nantes 